\title{
Curcumin in Cell Death Processes: A Challenge for CAM of Age-Related Pathologies
}

\author{
S. Salvioli ${ }^{1,2}$, E. Sikora ${ }^{3}$, E. L. Cooper ${ }^{4}$ and C. Franceschi ${ }^{1,2,5}$
}

${ }^{1}$ Department of Experimental Pathology and Centro Interdipartimentale "L. Galvani", University of Bologna,

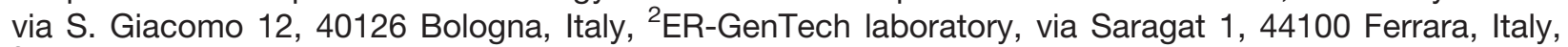
${ }^{3}$ Department of Cellular Biochemistry, Nencki Institute of Experimental Biology, 3 Pasteura St., 02-093 Warsaw, Poland, ${ }^{4}$ Laboratory of Comparative Neuroimmunology, Department of Neurobiology, David Geffen School of Medicine at UCLA, University of California at Los Angeles, Los Angeles California 90095-1763 and ${ }^{5}$ I.N.R.C.A., Department of Gerontological Sciences, via Birarelli 8, 60121 Ancona, Italy

Curcumin, the yellow pigment from the rhizoma of Curcuma longa, is a widely studied phytochemical which has a variety of biological activities: anti-inflammatory and anti-oxidative. In this review we discuss the biological mechanisms and possible clinical effects of curcumin treatment on cancer therapy, and neurodegenerative diseases such as Alzheimer's Disease, with particular attention to the cell death processes induced by curcumin. Since oxidative stress and inflammation are major determinants of the aging process, we also argue that curcumin can have a more general effect that slows down the rate of aging. Finally, the effects of curcumin can be described as xenohormetic, since it activates a sort of stress response in mammalian cells.

Keywords: aging-apoptosis-cancer-curcumin-neurodegenerative diseases-xenohormesis

\section{Introduction: A Natural Treatment for Cancer and Other Age-related Diseases}

\section{Curative Properties Against Cancer}

For many centuries, turmeric has been used throughout Asia as a food additive and a traditional herbal medicine as well. Curcumin (diferuloylmethane), the yellow pigment extracted from the rhizoma of Curcuma longa, is the pharmacologically active substance of turmeric. Curcumin is nontoxic and has a variety of positive pharmacological effects: indeed, anti-oxidative, anti-inflammatory and antiseptic properties have been reported (1-3). Curcumin also has several of biological activities that eventually render this molecule a possible anti-cancer drug, as both chemopreventive and chemotherapeutic. Indeed, many lines

For reprints and all correspondence: Prof. Claudio Franceschi, Department of Experimental Pathology and Centro Interdipartimentale "L. Galvani”, University of Bologna, via S. Giacomo 12, 40126 Bologna, Italy. E-mail: claudio.franceschi@unibo.it of evidence indicate that curcumin contributes to the inhibition of tumor formation, promotion, progression and dissemination in many animal models (4). In particular, curcumin can inhibit both tumor initiation induced by benzo[a]pyrene and 7,12 dimethylbenz[a]anthracene (5) and tumor promotion by phorbol esters (6,7). Dietary administration of curcumin significantly inhibits skin, oral, forestomach, duodenal, colon and tongue carcinogenesis in mice and rats (8-11). As a whole, this body of evidence has strongly suggested that curcumin can be considered a promising tool for cancer therapy and, in recent years, a number of Phase I human trials have been performed, showing this compound to be well-tolerated (12-15). Overall, these studies confirmed the lack of toxicity of curcumin administration and also suggested a biologic effect of curcumin in the chemoprevention of cancer.

\section{Other Known Treatments}

Beside cancer, curcumin is considered a promising drug for the treatment of other diseases, most of which are 
related to the aging process. Indeed curcumin has an anti-oxidant and anti-inflammatory activity, as mentioned above, so it could likely ameliorate a series of pathogenetic conditions that share an inflammatory or oxidative basis, such as cardiovascular diseases, sporadic Alzheimer's disease (AD), sarcopenia, type II diabetes, arthrosis and arthritis among others (16-21). In recent years, curcumin is also proposed as a possible tool to cure, or at least ameliorate, cystic fibrosis $(22,23)$.

\section{Inflamm-aging}

We recently suggested that successful aging derives from the capability to cope with inflammatory responses evoked by long-lasting stressors (24). Such stressors can induce a chronic pro-inflammatory status characteristic of aging that we have proposed to call 'inflamm-aging' (25). Stressor agents can include physiochemical and biotic agents like viral and bacterial antigens, UV rays, environmental chemicals and so on. The response to such agents is mostly of inflammatory type, and consequently, a chronic exposure to these agents induces an increase in inflammatory markers in the elderly. If anti-inflammatory mechanisms fail to counteract such responses, inflammation-based diseases eventually occur. In this perspective, drugs that can change the balancing between inflammation and anti-inflammation toward anti-inflammation can, at least in theory, help in avoiding, delaying or diminishing inflammation-based diseases.

\section{Oxidative Stress}

Oxidative stress, and the consequent accumulation of molecules damaged by oxidant by-products of respiratory metabolism, is considered a major cause of aging (26). Most agents that activate a major transcription factor, such as NF- $\mathrm{BB}$, are either modulated by oxidative stress or are pro-oxidants themselves (27) or are oxidized molecules, such as Large Density Lipoproteins (28). Many genes coding for pro-inflammatory cytokines are mainly transcripted upon NF- $\mathrm{NB}$ activation, thus oxidative stress (mostly due to mitochondrial metabolism) can impinge upon the aging process through inflammatory reactions, and pro-inflammatory cytokines can be the link between aging and oxidative stress (29). One of the most important cellular defense mechanisms against oxidative stress or electrophiles is mediated by the transcription factor $\mathrm{Nrf2}$ (30). Once activated, Nrf2 is able to activate the antioxidant-responsive element (ARE)-dependent gene expression in order to maintain cellular redox homeostasis. Curcumin can stimulate the expression of $\mathrm{Nrf} 2$ in a concentration- and timedependent manner (31). Thus, curcumin can counteract the effect of oxidative stress through this pathway and help in avoiding, delaying or slowing down aging as well as age-related diseases that share an oxidative damage, such as the complications of type II diabetes (32).

Taking into consideration that curcumin is provided with anti-proliferative and pro-apoptotic activities, as well as anti-oxidant and anti-inflammatory capabilities, it is reasonable to propose that curcumin (and likely other phytochemicals) should be considered a possible tool to complement pharmacological therapies not only for cancer but also for many other age-related diseases, including neurodegeneration and chronic inflammation. We will briefly summarize the effects of curcumin by focusing in particular on cell death, and the consequences of such effects on neurodegeneration and aging. Finally, we will speculate on curcumin's action as a possible example of xenohormesis.

\section{Curcumin and Cell Death}

\section{Molecular Targets}

According to one hypothesis, the anti-cancer activity of curcumin may originate, at least in part, from its capability to induce antioxidant and phase II metabolizing enzymes involved in detoxification, as observed in ddY male mice (33). Nevertheless, several different curcumin activities with potential anticancer effects have been reported $(4,34,35)$. Evidently from the review of Aggarwal et al. (34) curcumin suppresses proliferation of a wide variety of tumor cells, down-regulates transcription factors such as NF- $\kappa \mathrm{B}, \mathrm{AP}-1$ and Egr-1; down-regulates the expression of Cyclooxygenase-2, Lipooxygenase, Nitric Oxide Synthase, Matrix metalloproteinase 9, urokinase-type Plasminogen Activator, tumor necrosis factor (TNF), chemokines, cell surface adhesion molecules and cyclin D1; down-regulates growth factor receptors (such as EGFR and HER2); and inhibits the activity of c-Jun N-terminal kinase, protein tyrosine kinases and protein serine/threonine kinases. Furthermore, curcumin has an anti-angiogenic activity (3) and it can induce cell death in a wide variety of in vitro cancer and noncancer cell cultures. A number of excellent reviews do already exist on this topic $(4,34-36)$. We will focus on the capability of curcumin to induce different processes of cell death by analyzing the underlying molecular mechanisms. We will also consider the biphasic behavior of curcumin, and the possibility that curcumin cannot only induce but also protect against cell death.

In in vitro studies, curcumin inhibits proliferation and/or induces cell death in many different cell types. The most common cell death process induced upon curcumin treatment seems to be apoptosis, even if other processes (necrosis, mitotic catastrophe, see subsequent text) cannot be excluded. Accordingly, curcumin is known to induce apoptosis in numerous animal and human cell lines, like leukemia, melanoma, breast, lung, prostate, colon, renal, hepatocellular and ovarian carcinomas [reviewed in (37) and (38)]. 


\section{Apoptosis}

Curcumin can induce the mitochondrial-dependent apoptotic pathway, as the release of cytochrome $\mathrm{c}$ and other proapoptogenic mitochondrial factors such as AIF have been shown in different human cells upon curcumin treatment $(38,39)$, although a Fas/caspase-8 pathway has also been observed (40). Curcumin-induced apoptosis has been reported to be p53-dependent $(41,42)$. However, we have observed that apoptotic phenomena also occur in p53-deficient HL-60 cells upon curcumin treatment $(43,44)$, and other authors also showed that the curcumin-induced apoptosis of lung and colon cancer cells appears to be p53-independent (45). Similarly, the role of Bcl-2 family proteins in the curcumin-induced apoptosis remains elusive (45-47). Moreover the role of reactive oxygen species (ROS) in curcumin-induced apoptosis is controversial, since curcumin can exert both pro- and anti-oxidant effects (48). In fact, sensitivity of many tumor cells to curcumin correlates with generation of ROS (49) and many well-known antioxidants prevent curcumin-induced apoptosis (50). At the same time however, curcumin is a potent scavenger of ROS (51) and increases the level of glutathione $(52,53)$.

This plethora of curcumin's effects can be explained by the pleiotropic activity of curcumin on the one hand, and by its activity on gene transcription regulation on the other. Indeed, curcumin inhibits AP-1 transcription factor, which is involved in apoptotic program and regulation of cell proliferation of many cells (54-56). Similarly, NF- $\kappa \mathrm{B}$ transcription factor, which is involved in pro-survival and apoptotic pathways, is inhibited by curcumin (57-60). Recently, curcumin has been shown to repress histone acetyltransferase-dependent chromatin transcription by inhibiting its p300/CREB-binding protein (61). p300 is a ubiquitously expressed global transcriptional coactivator that plays critical roles in various cellular phenomena including cell cycle control, differentiation and apoptosis (62).

\section{Non-Apoptotic Cell Death: Mitotic Catastrophe}

Clearly we are far away from completely elucidating the mechanisms of curcumin-induced cell death. However, curcumin is an extremely powerful inducer of cancer cell death and it can overcome resistance to many apoptosisinducing factors by activating alternative apoptotic pathways or another type of cell death, namely mitotic catastrophe. Accordingly, we showed that curcumin can overcome the resistance of HL-60 cells with a multiple drug resistant phenotype (44), as well as the resistance of calcitriol-differentiated HL-60 cells to DNA-damageinduced apoptosis by activating other cell signaling pathways leading to cell death (63). Other studies from our group also demonstrated that curcumin can overcome the broad resistance to cell death caused by expression of Bcr-Abl in mouse cells (64) as well as of the HL-60-derived HCW-2 cell line that is highly resistant to apoptosis (65). These cells upon curcumin treatment undergo mitotic catastrophe, which is terminated by caspase 3 activation and oligonucleosomal DNA degradation. The term mitotic catastrophe indicates a form of cell death that is caused by aberrant mitosis. Mitotic catastrophe is associated with the formation of multinucleate, giant cells that contain uncondensed chromosomes, and is morphologically distinct from apoptosis (66). It seems that the target for curcumin action in mitotic catastrophe is Survivin, a modulator of cell division and apoptosis in cancer. It is also postulated that curcumin can counteract the induction of prosurvival factors by radio/chemoteraphy, thus potentiating the effect of chemotherapy and inhibiting metastasis dissemination (54).

\section{Enhancing Cytotoxicity}

Concomitantly with these and other data showing that curcumin enhances the cytotoxicity of chemotherapeutic agents $(57,58,67,68)$, there are reports that show a protective effect of curcumin against apoptosis induced by other factors $(52,56,69)$. Obviously, some discrepancy can be explained by the pleiotropic activity of curcumin, which has many molecular targets inside the cell. However, many of the aforementioned studies, including ours, are based on the assumption that apoptosis is characterized (and should be detected) by oligonucleosomal DNA degradation. This can be a misleading concept, since it has been reported that cell death can occur independently from DNA degradation (70), and very recently we showed that curcumin can induce cell death of Jurkat cells despite a simultaneous inhibitory effect on DFF40/CAD endonuclease activity (71). Thus, it is possible that discrepancy of data on protection against cell death by curcumin can be accounted for, at least in part, by this methodological bias, taking into account that the symptoms of cell death induced by curcumin can be different and depend on the cell context.

\section{Proteasome Activation}

Another possible explanation for these discrepancies relies on the capability of curcumin to exert a biphasic effect, depending on its concentration. As an example of such a behavior, Ali and Rattan recently reported that curcumin at different concentrations has a biphasic effect of proteasome activity in keratinocytes (72). It was previously reported that curcumin inhibited proteasome activity (73). In their paper, Ali and Rattan show that curcumin treatment (up to $1 \mu \mathrm{M}$ for $24 \mathrm{~h}$ ) increased chymotrypsin-like activity of the proteasome by $46 \%$ compared with that in untreated keratinocytes. However, higher concentrations of curcumin were inhibitory, 
and at $10 \mu \mathrm{M}$ the proteasome activity decreased to $46 \%$ of its initial value. Taking into account that proteasome inhibition induces apoptosis, while proteasome activation promotes cell survival, it is conceivable that a biphasic behavior of curcumin on proteasome can lead to either apoptosis or survival, depending on the dose used. The biphasic effect of curcumin can also impinge on the type of cell death. In one report curcumin induces apoptotic changes, including JNK activation, caspase-3 activation, and cleavage of PARP and PAK2, at concentrations lower than $25 \mu \mathrm{M}$ in human osteoblast cells, while treatment with $50-200 \mu \mathrm{M}$ does not induce apoptosis, but rather triggers necrotic cell death (74). While treatment with $12.5-25 \mu \mathrm{M}$ curcumin directly increased intracellular oxidative stress, 50-200 $\mu \mathrm{M}$ curcumin had far less effect. Pretreatment of cells with N-acetyl cysteine or alphatocopherol, that are ROS scavengers, attenuated the intracellular ROS levels increase and converted the apoptosis to necrosis induced by $12.5-25 \mu \mathrm{M}$ curcumin. A dose-dependent decrease in intracellular ATP levels after treatment of osteoblast cells with curcumin was observed and pre-treatment of cells with antimycin or 2-deoxyglucose to cause ATP depletion significantly converted $12.5-25 \mu \mathrm{M}$ curcumin-induced apoptosis to necrosis. This is in agreement also with previously published data indicating that ATP levels are crucial in the apoptosis/necrosis switching mechanism (75). It appears from this study that curcumin dosage treatment determines the possible effect on ROS generation, intracellular ATP levels, and cell apoptosis or necrosis in osteoblast cells. Another example of biphasic activity is given by the temporal effect of curcumin on NF- $\mathrm{KB}$. Notarbartolo et al. reported an increase in NF- $\kappa$ B levels after $8 \mathrm{~h}$ of treatment and a decrease after 16h (76).

\section{Inhibition of hTERT}

Another possible activity of curcumin able to induce cell death processes is the inhibition of hTERT, the active subunit of telomerase $(77,78)$. In MCF-7 cells, telomerase activity decreased with increasing concentrations of curcumin, inhibiting about $93.4 \%$ activity at $100 \mu \mathrm{M}$ concentration. The inhibition of telomerase activity in MCF-7 cells may be due to down-regulation of hTERT expression. Increasing concentrations of curcumin caused a steady decrease in the level of hTERT mRNA in MCF-7 cells, whereas the level of hTER and c-myc mRNAs remained the same. hTERT is activated in cancer cells and prevents telomere shortening and thus the activation of apoptotic processes. The inhibition of hTERT is an additional mechanism by which curcumin can induce cell death in cancer cells (79).

Among the targets of curcumin there is also the mammalian target of rapamycin (mTOR), an important regulator of autophagic cell death (80). At physiological concentrations $(2.5 \mu \mathrm{M})$, curcumin rapidly inhibits phosphorylation of mTOR and its downstream effector molecules, p70 S6 kinase 1 (S6K1) and eukaryotic initiation factor 4E (eIF4E) binding protein 1 (4E-BP1), in a panel of cell lines (Rh1, Rh30, DU145, MCF-7 and HeLa). Curcumin also inhibits phosphorylation of Akt in these cells, but only at high concentrations $(>40 \mu \mathrm{M})(80)$. Since mTOR is a pivotal player of autophagy, we speculate that curcumin may execute its cell death activity also through the induction of such a mechanism. Finally, curcumin can induce apoptosis via ER stress in HL-60 cells (81). On the whole, all the aforementioned data indicate that curcumin can induce cell death via different molecular pathways and with different executing mechanisms, i.e. classical apoptosis, but also mitotic catastrophe, necrosis and maybe autophagy (Fig. 1).

\section{Targets for Anti-cancer Drugs}

Several next generation anti-cancer drugs are emerging, among which there are, as examples, monoclonal antibodies that target $\mathrm{p} 53, \mathrm{NF}-\mathrm{\kappa B}$, AKT and Peroxisone Proliferator-Activated Receptor gamma, and small molecules that inhibit oncogenic tyrosine kinases. Many of these proteins are also a target for curcumin and other phytochemicals, and thus advanced multidrug protocols of cancer treatment could envisage the use of curcumin as an adjuvant drug to increase treatment efficacy. Nevertheless, since curcumin has such a wide range of targets, it is possible, at least in principle, that it can counteract rather than potentiate the effect of therapy in some types of cancer. For example, there are reports that curcumin can inhibit chemotherapeutic effects by reducing camptothecin-, mechlorethamine- or doxorubicin-induced apoptosis in breast cancer cells (68). These findings clearly suggest that each possible interaction between curcumin and other drugs used in therapy must be examined carefully before clinical use, especially when treatments of cancer are considered. Indeed, we should remember that in in vitro experiments curcumin can also induce cell death in normal cells, such as rat thymocytes and human $\mathrm{T}$ cells $(44,82,83)$.

\section{Curcumin and the Nervous System: A More Sensitive Target is Neuroprotection}

Beside cancer, another condition in which cell death processes are deeply involved is neurodegeneration. In the central nervous system of rats, curcumin exerts a protective effect against neurodegeneration $(84,85)$. Possible mechanisms of neuroprotection exerted by curcumin include inhibition of glutamate-mediated excytotoxicity, antioxidant activity, and induction of chaperone proteins. Indeed, in cultured neurons, treatment with curcumin reduced cell demise mediated by glutamate-induced 


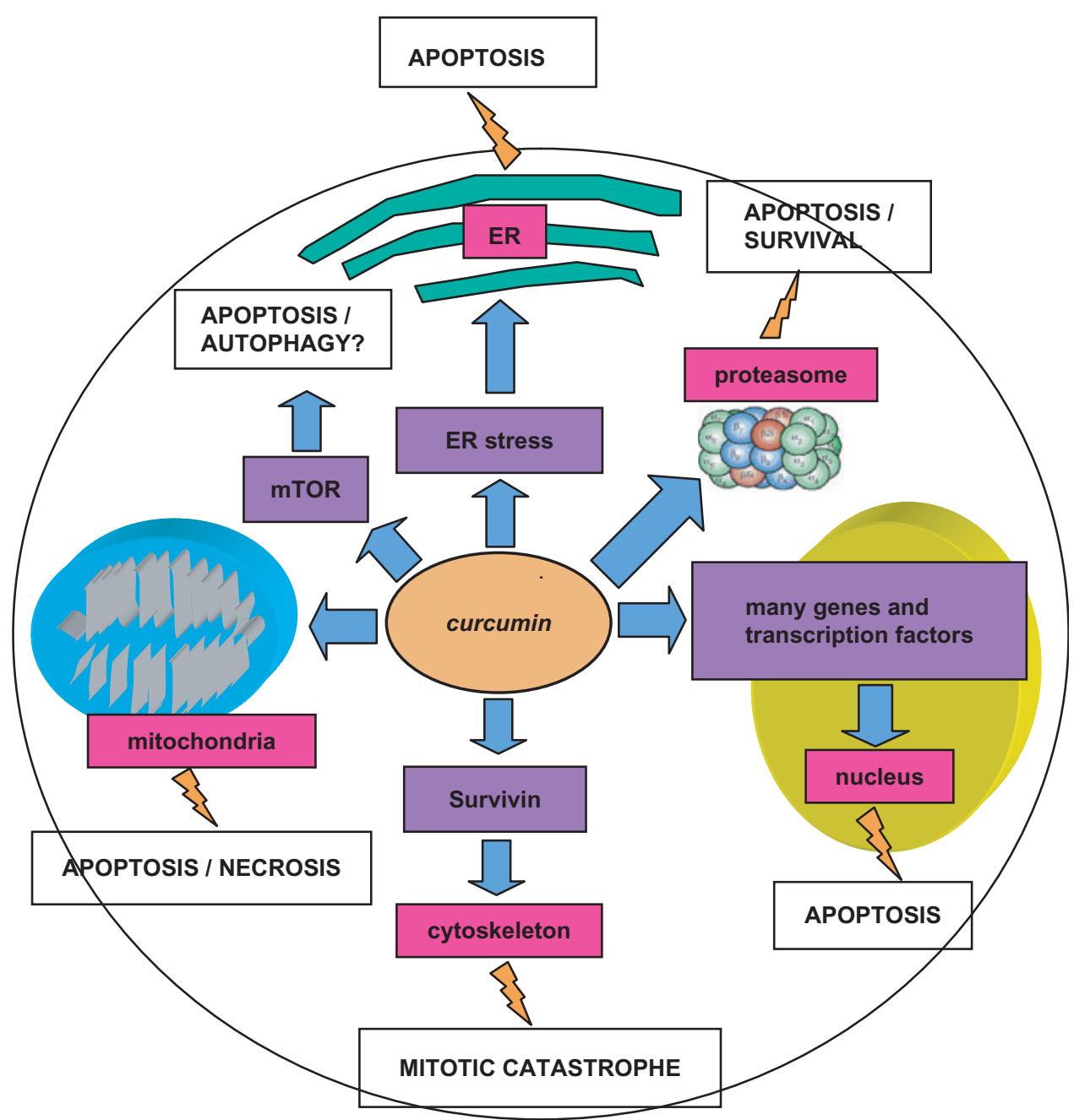

Figure 1. Main molecular targets of curcumin that lead to different types of cell death. Flashes indicate the main biological end points preceding cell death. DFF40: CAD DNA endonuclease; hTERT: telomerase catalytic subunit; ER: endoplasmic reticulum; mTOR: mammalian Target Of Rapamycin, Survivin: IAP family member involved in cytoskeleton stability.

$\mathrm{Ca}(2+)$ influx and caspase-3 activation (86). In another in vivo study, parkinsonian neurotoxin (MPTP)-induced GSH depletion and lipid peroxidation in rat striatum and mid-brain was blocked by curcumin treatment (87). Finally, AD and other neurodegenerative diseases such as Parkinson's and Huntington's disease, amyotrophic lateral sclerosis and Friedreich's ataxia, can have define as pathogenic moment the production of abnormally aggregated proteins. The pathogenic aggregation of proteins in non-native conformation is generally associated with metabolic derangements and excessive production of ROS. The correct folding of the proteins is carried out by heat-shock proteins, a group of proteins that are highly conserved through evolution. Curcumin not only serves as an antioxidant but, in addition, it is a strong inducer of the heat-shock response $(88,89)$. Moreover, it is reported that curcumin avoids lipid peroxidation, lipofuscin and $\beta$-amyloid (A- $\beta$ ) accumulation and cognitive impairments in rats $(85,90,91)$.
These animal studies suggest a possible direct protective action toward $\mathrm{AD}$ and represent the rational basis for Phase II studies on patients with mild-to-moderate AD (92). The possible use of curcumin as a neuroprotective drug is of potentially enormous importance; indeed neurodegenerative diseases such as AD affect millions of people world-wide and are becoming a dramatic health emergency in developed countries. Nevertheless, this curcumin activity at the level of central nervous system raises a question about its pharmacokinetics. Indeed, the main limitation of curcumin-based therapies appears at present to be the low bioavailability of such a drug outside the gastrointestinal tract. This limitation may be overcome by different strategies, one of which is the synthesis of curcumin-related analogs with similar or even increased pharmacological activity (93-95). These compounds could be linked to delivery systems that can focus the drug directly to target cells, thus overcoming the problem of poor bioavailability of curcumin (95). 


\section{Curcumin and Aging: An Ancient and Contemporary Frontier}

Information indicates that longevity results from the combination of genetic, environmental and stochastic components (96). Aging is thought to be a passive process not genetically determined that results from two opposite phenomena: a deterioration process occurring at molecular, cellular and organismal levels due to exposure to damaging agents on the one hand, and the action of many enzymatic and non-enzymatic systems that attempt to counteract such deterioration (remodeling) on the other. This latter phenomenon can occur to a different extent of efficacy because of genetic or environmental parameters. The most efficient is the system that deals with deteriorative process, the longer living will be the organism, and the more delayed will be the aging process. The genetic background of every individual can (still) not be changed; while it is possible to envisage interventions on the environment that can help in retarding the aging process.

To this end, the use of phytochemicals such as curcumin can be considered. Indeed, as mentioned above, curcumin exerts powerful anti-oxidant and antiinflammatory activities that can counteract two phenomena thought to be among the main causes of aging, i.e. inflammation and oxidative stress. Curcumin can thus be considered as a possible tool to slow down or delay senescence as well as the onset or progression of many age-related diseases. As far as apoptosis, several studies reveal that cells from aged individuals are more resistant to apoptosis vis a vis cells from younger subjects (97-99). In particular this phenomenon has been observed in peripheral blood mononuclear cells (lymphocytes and monocytes). A peculiar feature of immunosenescence (the aging process of the immune system) is indeed the accumulation of long-living memory cells that are highly resistant to apoptosis $(100,101)$. Such an accumulation, together with a decreased output of virgin lymphocytes from bone marrow leads to a decreased capacity of the immune system to cope with viral and bacterial infections and consequently to increased morbility and mortality.

In order to restore, at least partially, immune system function and delay immunosenescence, many different strategies have been proposed [for a review see (102)]. One strategy is to avoid the accumulation of long-living memory lymphocytes. Indeed, these cells, generated mainly in response to chronic exposure to common viral antigens such as Epstein-Barr virus and Cytomegalovirus, are weakly responding cells but do produce inflammatory cytokines (103-105). Thus, it is legitimate to predict that their deletion would lead to an improvement of the immune system in elderly individuals. Many purging techniques are technically available, even though they are quite unaffordable from an economic point of view and, most importantly, they would have an unpredictable impact on the whole organism (102). Perhaps, administration of dietary compounds such as curcumin can protect organisms not only against proliferative pathologies (cancer chemoprevention) as discussed, but also can maintain the susceptibility to apoptosis of memory lymphocytes. Thus curcumin can theoretically contrast the decline of immune function and eventually the process of aging. Once again this possibility must be experimentally tested, since levels of curcumin outside the gastrointestinal tract could be insufficient to induce such an effect.

\section{Conclusions 1: Curcumin as a Pleiotropic Anti-aging Factor?}

Curcumin is an approved food additive that appears to have substantial beneficial effects as it has anti-oxidant, anti-inflammatory and anti-proliferative activities. These activities and the main recognized molecular targets of curcumin are depicted in Fig. 2. Due to these actions, curcumin can impinge upon several conditions (represented as circles in the figures), among which cancer, neurodegeneration and aging are the most important. In this review we focused mainly on the effects on apoptosis and the consequences of such effects in neurodegeneration and aging. According to present knowledge, apoptosis is mainly involved in the first two conditions, i.e. cancer and neurodegeneration, while aging is likely more affected by inflammation. Nevertheless, as discussed in the previous paragraph, it is possible that a modulation of the susceptibility to apoptosis of immune cells could impinge upon the aging process. To conclude, curcumin appears to have positive effects on cancer, neurodegeneration and possibly aging through its capability to modulate cell death. It is interesting to note however that there is, to our knowledge, a lack of data on animal models regarding the effects of curcumin administration on animal life span, similar to those obtained for other phytochemicals such as resveratrol. These kinds of studies are urgently needed in order to assess whether curcumin does really impact on aging and longevity and whether it should be considered as a possible pharmaceutical tool to delay the aging process.

\section{Conclusions 2: Is the Effect of Curcumin an Example of Xenohormesis?}

Curcumin appears to possess all the desirable features of a desk-designed, multipurpose drug. Why should a phytochemical such as curcumin be so effective in human cells? It is well-known that other xenobiotics exert beneficial effects in humans, e.g. fungine antibiotics. Nevertheless in this case, the beneficial effects are largely independent of the host organism, while in the case of phytochemicals, these effects are basically due to 


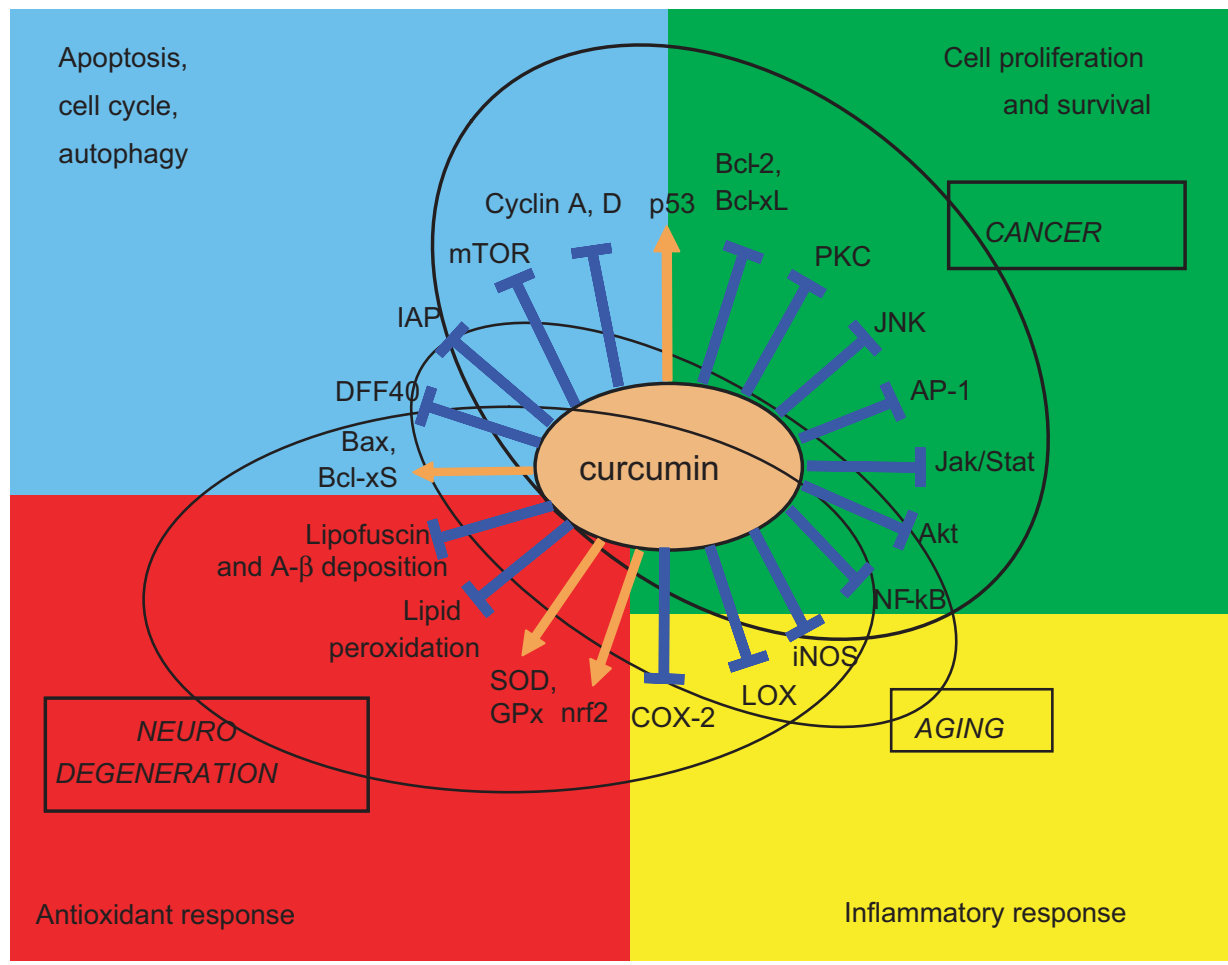

Figure 2. Main molecular targets of curcumin divided in biological action (apoptosis, cell proliferation, antioxidant response, inflammatory response). Orange arrows indicate enhancement, blue lines indicate inhibition. Circles group molecules involved in the indicated processes (aging, cancer, neurodegeneration). DFF40: CAD DNA endonuclease; IAP: Inhibitor of Apoptosis Protein family; GPx: Glutathione Peroxidase; mTOR: mammalian Target Of Rapamycin; A- $\beta$ : beta-amyloid; iNOS: inducible Nitric Oxide Synthase.

activation of host response mechanisms. This is a completely different strategy to induce protection toward noxae in an organism, for which we can identify hormesis $(106,107)$. The term 'hormesis' refers to beneficial actions resulting from the response of an organism to a low-intensity stressor. Many of the phytochemicals present in vegetables and fruits may have evolved as toxins (to dissuade insects and other predators) that, at subtoxic doses, activate adaptive cellular stress-response pathways (108). This seems not to be the case curcumin, which is nontoxic even at high doses, so a different concept of hormesis should be considered. As proposed by Sinclair and Howitz, organisms can pick up on chemical stress cues from other species under stress, either in their food or environment, and use these to activate their own defense pathways in preparation for adverse conditions (109-111).

This idea is known as 'the Xenohormesis Hypothesis'. According to this hypothesis, curcumin and other phytochemicals could have been selected in plants as upstream stress signaling molecules able to induce a protective response toward different types of stresses (UV, drought, diseases, insect attack, etc.). Phylogenetic studies suggest that plants and animals largely share the same molecular pathways in order to respond to stress, so it is conceivable that a molecule produced in plants can be effective also in animals, and particularly in mammals and humans as well. Thus, the effect of these phytochemicals could be present also in organisms different from which they were derived. Ali and Rattan have recently proposed that curcumin could be a useful 'hormetin' for a series of different treatments (72). A xenohormetic mechanism of curcumin would also fit with its very broad range of effects. The phenomenon of xenohormesis directly comes from heterotrophy, that is, the dependence for survival on eating other organisms. In this case heterotrophy would concern not only caloric intake and micronutrients, but also the intake of such molecules with pharmacological activities. Eat something to acquire its own qualities is an ancestral idea of mankind. Curcumin demonstrates the advantage of such an idea and xenohormesis can explain why.

\section{Acknowledgments}

This work was supported by: EU Projects 'PROTEOMAGE' Contract n FP6-518230 and 'GEHA - Genetics of Healthy Aging' FP6-503270 Grants; the PRRIITT program of the Emilia-Romagna Region (and Fondi Strutturali Obiettivo 2); FISM (Federazione Italiana Sclerosi Multipla) Grant (Finalised Project 'Immunoproteasome in Multiple Sclerosis: Genetics and Biological Role in the Pathogenesis of the Disease') 
to $\mathrm{CF}$; University of Bologna Ricerca Fondamentale Orientata (RFO 2005), and Roberto and Cornelia Pallotti Legacy for Cancer Research Grants to CF and SS. ELC was Senior Visiting Scientist, Institute for Advanced Studies, University of Bologna.

\section{References}

1. Bengmark S. Curcumin, an atoxic antioxidant and natural NFkappaB, cyclooxygenase-2, lipooxygenase, and inducible nitric oxide synthase inhibitor: A shield against acute and chronic diseases. JPEN J Parenter Enteral Nutr 2006;30:45-51.

2. Nishino H, Tokuda H, Satomi Y, Masuda M, Osaka Y, Yogosawa S, et al. Cancer prevention by antioxidants. Biofactors 2004:22:57-61.

3. Maheshwari RK, Singh AK, Gaddipati J, Srimal RC. Multiple biological activities of curcumin: A short review. Life Sci 2006:78:2081-7.

4. Duvoix A, Blasius R, Delhalle S, Schnekenburger M, Morceau F, Henry E, et al. Chemopreventive and therapeutic effects of curcumin. Cancer Lett 2005;223:181-90.

5. Huang MT, Wang ZY, Georgiadis CA, Laskin JD, Conney AH. Inhibitory effects of curcumin on tumor initiation by benzo[a]pyrene and 7,12-dimethylbenz[a]anthracene. Carcinogenesis 1992;13:2183-6.

6. Conney AH, Lysz T, Ferraro T, Abidi TF, Manchand PS, Laskin JD, et al. Inhibitory effect of curcumin and some related dietary compounds on tumor promotion and arachidonic acid metabolism in mouse skin. Adv Enzyme Regul 1991;31:385-96.

7. Huang MT, Lou YR, Xie JG, Ma W, Lu YP, Yen P, et al. Effect of dietary curcumin and dibenzoylmethane on formation of 7,12-dimethylbenz[a]anthracene-induced mammary tumors and lymphomas/leukemias in Sencar mice. Carcinogenesis 1998;19:1697-700.

8. Azuine MA, Bhide SV. Chemopreventive effect of turmeric against stomach and skin tumors induced by chemical carcinogens in Swiss mice. Nutr Cancer 1992;17:77-83.

9. Azuine MA, Bhide SV. Adjuvant chemoprevention of experimental cancer: catechin and dietary turmeric in forestomach and oral cancer models. J Ethnopharmacol 1994;44:211-7.

10. Huang MT, Lou YR, Ma W, Newmark HL, Reuhl KR, Conney AH. Inhibitory effects of dietary curcumin on forestomach, duodenal, and colon carcinogenesis in mice. Cancer Res 1994;54:5841-7.

11. Rao CV, Rivenson A, Simi B, Reddy BS. Chemoprevention of colon carcinogenesis by dietary curcumin, a naturally occurring plant phenolic compound. Cancer Res 1995;55:259-66.

12. Cheng AL, Hsu CH, Lin JK, Hsu MM, Ho YF, Shen TS, et al. Phase I clinical trial of curcumin, a chemopreventive agent, in patients with high-risk or pre-malignant lesions. Anticancer Res 2001;21:2895-900.

13. Hsu CH, Chuang SE, Hergenhahn M, Kuo ML, Lin JK, Hsieh CY, et al. Pre-clinical and early-phase clinical studies of curcumin as chemopreventive agent for endemic cancers in Taiwan. Gan To Kagaku Ryoho 2002;29:194-200.

14. Sharma RA, Euden SA, Platton SL, Cooke DN, Shafayat A, Hewitt HR, et al. Phase I clinical trial of oral curcumin: Biomarkers of systemic activity and compliance. Clin Cancer Res 2004;10:6847-54.

15. Bemis DL, Katz AE, Buttyan R. Clinical trials of natural products as chemopreventive agents for prostate cancer. Expert Opin Investig Drugs 2006;15:1191-200.

16. Tohda C, Nakayama N, Hatanaka F, Komatsu K. Comparison on anti-inflammatory activities of six Curcuma rhizomes: A possible curcuminoid-independent pathway mediated by Curcuma phaeocaulis extract. Evid Based Complement Alternat Med 2006;3:255-60.

17. Ahmed S, Anuntiyo J, Malemud CJ, Haqqi TM. Biological basis for the use of botanicals in osteoarthritis and rheumatoid arthritis: A review. Evid Based Complement Alternat Med 2005;2:301-8.

18. Cooper EL. Regional strength in CAM. Evid Based Complement Alternat Med 2006:3:291-2.

19. Ramnath V, Rekha PS, Sujatha KS. Amelioration of heat stress induced disturbances of antioxidant defense system in chicken by
Brahma rasayana. Evid Based Complement Alternat Med advance access, in press.

20. Olalde Rangel JA, Magarici M, Amendola F, del Castillo O. The systemic theory of living systems. Part IV: Systemic medicine - The praxis. Evid Based Complement Alternat Med 2005;2:429-39.

21. Punitha ISR, Rajendran K, Shirwaikar A, Shirwaiker A. Alcoholic stem extract of Coscinium fenestratum regulates carbohydrate metabolism and improves antioxidant status in streptozotocin nicotinamide induced diabetic rats. Evid Based Complement Alternat Med 2005;2:375-81.

22. Egan ME, Pearson M, Weiner SA, Rajendran V, Rubin D, Glockner-Pagel J, et al. Curcumin, a major constituent of turmeric, corrects cystic fibrosis defects. Science 2004;304:600-2.

23. Zeitlin P. Can curcumin cure cystic fibrosis? $N$ Engl J Med 2004:351:606-8.

24. Franceschi C, Capri M, Monti D, Giunta S, Olivieri F, Sevini F, et al. Inflammaging and anti-inflammaging: A systemic perspective on aging and longevity emerged from studies in humans. Mech Ageing Dev 2007;128:92-105.

25. Franceschi C, Bonafe M, Valensin S, Olivieri F, De Luca M, Ottaviani E, et al. Inflamm-aging. An evolutionary perspective on immunosenescence. Ann N Y Acad Sci 2000;908:244-54.

26. Harman D. Aging: a theory based on free radical and radiation chemistry. J Gerontol 1956;11:298-300.

27. Chung HY, Kim HJ, Kim KW, Choi JS, Yu BP. Molecular inflammation hypothesis of aging based on the antiaging mechanism of calorie restriction. Microsc Res Tech 2002;59:264-72.

28. Robbesyn F, Salvayre R, Negre-Salvayre A. Dual role of oxidized LDL on the NF-kappaB signaling pathway. Free Radic Res 2004:38:541-51.

29. Salvioli S, Capri M, Valensin S, Tieri P, Monti D, Ottaviani E, et al. Inflamm-aging, Cytokines and Aging: state of the art, new hypotheses on the role of mitochondria and new perspectives from system biology. Curr Pharm Des 2006;12:3161-71.

30. Zhang DD. Mechanistic studies of the Nrf2-Keap1 signaling pathway. Drug Metab Rev 2006;38:769-89.

31. Balogun E, Hoque M, Gong P, Killeen E, Green CJ, Foresti R, et al. Curcumin activates the haem oxygenase- 1 gene via regulation of $\mathrm{Nrf} 2$ and the antioxidant-responsive element. Biochem $J$ 2003;371:887-95.

32. Ceriello A. Controlling oxidative stress as a novel molecular approach to protecting the vascular wall in diabetes. Curr Opin Lipidol 2006;17:510-8.

33. Iqbal M, Sharma SD, Okazaki Y, Fujisawa M, Okada S. Dietary supplementation of curcumin enhances antioxidant and phase II metabolizing enzymes in ddY male mice: Possible role in protection against chemical carcinogenesis and toxicity. Pharmacol Toxicol 2003;92:33-8.

34. Aggarwal BB, Kumar A, Bharti AC. Anticancer potential of curcumin: Preclinical and clinical studies. Anticancer Res 2003;23:363-98.

35. Hemaiswarya S, Doble M. Potential synergism of natural products in the treatment of cancer. Phytother Res 2006;20:239-49.

36. D'Incalci M, Steward WP, Gescher AJ. Use of cancer chemopreventive phytochemicals as antineoplastic agents. Lancet Oncol 2005;6:899-904.

37. Karunagaran D, Rashmi R, Kumar TR. Induction of apoptosis by curcumin and its implications for cancer therapy. Curr Cancer Drug Targets 2005:5:117-29.

38. Rashmi R, Kumar S, Karunagaran D. Ectopic expression of Bcl-XL or Ku70 protects human colon cancer cells (SW480) against curcumin-induced apoptosis while their down-regulation potentiates it. Carcinogenesis 2004;25:1867-77.

39. Rashmi R, Kumar S, Karunagaran D. Human colon cancer cells lacking Bax resist curcumin-induced apoptosis and Bax requirement is dispensable with ectopic expression of Smac or downregulation of Bcl-XL. Carcinogenesis 2005;26:713-23.

40. Anto RJ, Mukhopadhyay A, Denning K, Aggarwal BB. Curcumin (diferuloylmethane) induces apoptosis through activation of caspase-8, BID cleavage and cytochrome c release: its suppression by ectopic expression of $\mathrm{Bcl}-2$ and $\mathrm{Bcl}-\mathrm{xl}$. Carcinogenesis 2002;23:143-50 
41. Choudhuri T, Pal S, Agwarwal ML, Das T, Sa G. Curcumin induces apoptosis in human breast cancer cells through p53-dependent Bax induction. FEBS Lett 2002;512:334-40.

42. Song G, Mao YB, Cai QF, Yao LM, Ouyang GL, Bao SD. Curcumin induces human HT-29 colon adenocarcinoma cell apoptosis by activating p53 and regulating apoptosis-related protein expression. Braz J Med Biol Res 2005;38:1791-8.

43. Bielak-Zmijewska A, Koronkiewicz M, Skierski J, Piwocka K, Radziszewska E, Sikora E. Effect of curcumin on the apoptosis of rodent and human nonproliferating and proliferating lymphoid cells. Nutr Cancer 2000;38:131-8.

44. Bielak-Zmijewska A, Piwocka K, Magalska A, Sikora E. P-glycoprotein expression does not change the apoptotic pathway induced by curcumin in HL-60 cells. Cancer Chemother Pharmacol 2004;53:179-85.

45. Radhakrishna Pillai G, Srivastava AS, Hassanein TI, Chauhan DP, Carrier E. Induction of apoptosis in human lung cancer cells by curcumin. Cancer Lett 2004;208:163-70.

46. Mukhopadhyay A, Bueso-Ramos C, Chatterjee D, Pantazis P, Aggarwal BB. Curcumin downregulates cell survival mechanisms in human prostate cancer cell lines. Oncogene 2001;20:7597-609.

47. Piwocka K, Zablocki K, Wieckowski MR, Skierski J, Feiga I, Szopa J, et al. A novel apoptosis-like pathway, independent of mitochondria and caspases, induced by curcumin in human lymphoblastoid T (Jurkat) cells. Exp Cell Res 1999;249:299-307.

48. Ahsan H, Parveen N, Khan NU, Hadi SM. Pro-oxidant, antioxidant and cleavage activities on DNA of curcumin and its derivatives demethoxycurcumin and bisdemethoxycurcumin. Chem Biol Interact 1999;121:61-175.

49. Khar A, Ali AM, Pardhasaradhi BV, Varalakshmi CH, Anjum R, Kumari AL. Induction of stress response renders human tumor cell lines resistant to curcumin-mediated apoptosis: Role of reactive oxygen intermediates. Cell Stress Chaperones 2001;6:368-76.

50. Kuo ML, Huang TS, Lin JK. Curcumin, an antioxidant and anti-tumor promoter, induces apoptosis in human leukemia cells. Biochim Biophys Acta 1996;1317:95-100.

51. Fujisawa S, Atsumi T, Ishihara M, Kadoma Y. Cytotoxicity, ROS-generation activity and radical-scavenging activity of curcumin and related compounds. Anticancer Res 2004;24:563-9.

52. Jaruga E, Bielak-Zmijewska A, Sikora E, Skierski J, Radziszewska E, Piwocka K, et al. Glutathione-independent mechanism of apoptosis inhibition by curcumin in rat thymocytes. Biochem Pharmacol 1998;56:961-5.

53. Piwocka K, Jaruga E, Skierski J, Gradzka I, Sikora E. Effect of glutathione depletion on caspase-3 independent apoptosis pathway induced by curcumin in Jurkat cells. Free Radic Biol Med 2001:31:670-8.

54. Aggarwal BB, Shishodia S. Molecular targets of dietary agents for prevention and therapy of cancer. Biochem Pharmacol 2006;71:1397-421.

55. Divya CS, Pillai MR. Antitumor action of curcumin in human papillomavirus associated cells involves downregulation of viral oncogenes, prevention of $\mathrm{NFkB}$ and $\mathrm{AP}-1$ translocation, and modulation of apoptosis. Mol Carcinog 2006;45:320-32.

56. Sikora E, Bielak-Zmijewska A, Piwocka K, Skierski J, Radziszewska E. Inhibition of proliferation and apoptosis of human and rat $\mathrm{T}$ lymphocytes by curcumin, a curry pigment. Biochem Pharmacol 1997;54:899-907.

57. Bharti AC, Shishodia S, Reuben JM, Weber D, Alexanian R, Raj-Vadhan S, et al. Nuclear factor-kappaB and STAT3 are constitutively active in CD138+ cells derived from multiple myeloma patients, and suppression of these transcription factors leads to apoptosis. Blood 2004:103:3175-84.

58. Deeb D, Xu YX, Jiang H, Gao X, Janakiraman N, Chapman RA, et al. Curcumin (diferuloyl-methane) enhances tumor necrosis factor-related apoptosis-inducing ligand-induced apoptosis in LNCaP prostate cancer cells. Mol Cancer Ther 2003;2:95-103.

59. Deeb D, Jiang H, Gao X, Hafner MS, Wong H, Divine G, et al. Curcumin sensitizes prostate cancer cells to tumor necrosis factorrelated apoptosis-inducing ligand/Apo2L by inhibiting nuclear factor-kappaB through suppression of IkappaBalpha phosphorylation. Mol Cancer Ther 2004;3:803-12.

60. Li L, Aggarwal BB, Shishodia S, Abbruzzese J, Kurzrock R. Nuclear factor-kappaB and IkappaB kinase are constitutively active in human pancreatic cells, and their down-regulation by curcumin (diferuloylmethane) is associated with the suppression of proliferation and the induction of apoptosis. Cancer 2004;101:2351-62.

61. Balasubramanyam K, Varier RA, Altaf M, Swaminathan V, Siddappa NB, Ranga U, et al. Curcumin, a novel p300/CREBbinding protein-specific inhibitor of acetyltransferase, represses the acetylation of histone/nonhistone proteins and histone acetyltransferase-dependent chromatin transcription. $J$ Biol Chem 2004;279:51163-71.

62. Giordano A, Avantaggiati ML. p300 and CBP: Partners for life and death. J Cell Physiol 1999;181:218-30.

63. Mosieniak G, Sliwinska M, Piwocka K, Sikora E. Curcumin abolishes apoptosis resistance of calcitriol-differentiated HL-60 cells. FEBS Lett 2006;580:4653-60.

64. Wolanin K, Magalska A, Mosieniak G, Klinger R, McKenna S, Vejda S, et al. Curcumin affects components of the chromosomal passenger complex and induces mitotic catastrophe in apoptosisresistant Bcr-Abl-expressing cells. Mol Cancer Res 2006;4:457-69.

65. Magalska A, Sliwinska M, Szczepanowska J, Salvioli S, Franceschi C, Sikora E. Resistance to apoptosis of HCW-2 cells can be overcome by curcumin- or vincristine-induced mitotic catastrophe. Int J Cancer 2006;119:1811-8.

66. Okada H, Mak TW. Pathways of apoptotic and non-apoptotic death in tumour cells. Nat Rev Cancer 2004;4:592-603.

67. Chan MM, Fong D, Soprano KJ, Holmes WF, Heverling H. Inhibition of growth and sensitization to cisplatin-mediated killing of ovarian cancer cells by polyphenolic chemopreventive agents. $J$ Cell Physiol 2003;194:63-70.

68. Hour TC, Chen J, Huang CY, Guan JY, Lu SH, Pu YS. Curcumin enhances cytotoxicity of chemotherapeutic agents in prostate cancer cells by inducing $\mathrm{p} 21$ (WAF1/CIP1) and C/EBPbeta expressions and suppressing NF-kappaB activation. Prostate 2002;51:211-8.

69. Somasundaram S, Edmund NA, Moore DT, Small GW, Shi YY, Orlowski RZ. Dietary curcumin inhibits chemotherapy-induced apoptosis in models of human breast cancer. Cancer Res 2002;62:3868-75.

70. Barbieri D, Troiano L, Grassilli E, Agnesini C, Cristofalo EA, Monti D, et al. Inhibition of apoptosis by zinc: A reappraisal. Biochem Biophys Res Commun 1992;187:1256-61.

71. Sikora E, Bielak-Zmijewska A, Magalska A, Piwocka K, Mosieniak G, Kalinowska M, et al. Curcumin induces caspase-3dependent apoptotic pathway but inhibits DNA fragmentation factor 40 /caspase-activated DNase endonuclease in human Jurkat cells. Mol Cancer Ther 2006;5:927-34.

72. Ali RE, Rattan SI. Curcumin's biphasic hormetic response on proteasome activity and heat-shock protein synthesis in human keratinocytes. Ann N Y Acad Sci 2006;1067:394-9.

73. Jana NR, Dikshit P, Goswami A, Nukina N. Inhibition of proteasomal function by curcumin induces apoptosis through mitochondrial pathway. J Biol Chem 2004;279:11680-5.

74. Chan WH, Wu HY, Chang WH. Dosage effects of curcumin on cell death types in a human osteoblast cell line. Food Chem Toxicol 2006:44:1362-71.

75. Richter C, Schweizer M, Cossarizza A, Franceschi C. Control of apoptosis by the cellular ATP level. FEBS Lett 1996;378:107-10.

76. Notarbartolo M, Poma P, Perri D, Dusonchet L, Cervello M, D'Alessandro N. Antitumor effects of curcumin, alone or in combination with cisplatin or doxorubicin, on human hepatic cancer cells. Analysis of their possible relationship to changes in NF-kB activation levels and in IAP gene expression. Cancer Lett 2005;224:53-65.

77. Ramachandran C, Fonseca HB, Jhabvala P, Escalon EA, Melnick SJ. Curcumin inhibits telomerase activity through human telomerase reverse transcritpase in MCF-7 breast cancer cell line. Cancer Lett 2002;184:1-6.

78. Cui SX, Qu XJ, Xie YY, Zhou L, Nakata M, Makuuchi M, et al. Curcumin inhibits telomerase activity in human cancer cell lines. Int J Mol Med 2006;18:227-31.

79. Ramachandran C, Fonseca HB, Jhabvala P, Escalon EA, Melnick SJ. Curcumin inhibits telomerase activity through human telomerase reverse transcritpase in MCF-7 breast cancer cell line. Cancer Lett. 2002;184:1-6. 
80. Beevers CS, Li F, Liu L, Huang S. Curcumin inhibits the mammalian target of rapamycin-mediated signaling pathways in cancer cells. Int J Cancer 2006;119:757-64.

81. Pae HO, Jeong SO, Jeong GS, Kim KM, Kim HS, Kim SA, et al. Curcumin induces pro-apoptotic endoplasmic reticulum stress in human leukemia HL-60 cells. Biochem Biophys Res Commun 2007:353:1040-5.

82. Jaruga E, Salvioli S, Dobrucki J, Chrul S, Bandorowicz-Pikula J, Sikora E, et al. Apoptosis-like, reversible changes in plasma membrane asymmetry and permeability, and transient modifications in mitochondrial membrane potential induced by curcumin in rat thymocytes. FEBS Lett 1998:433:287-93.

83. Magalska A, Brzezinska A, Bielak-Zmijewska A, Piwocka K, Mosieniak G, Sikora E. Curcumin induces cell death without oligonucleosomal DNA fragmentation in quiescent and proliferating human CD8+ cells. Acta Biochim. Polon 2006;53:531-8.

84. Frank B, Gupta S. A review of antioxidants and Alzheimer's disease. Ann Clin Psychiatry 2005;17:269-86.

85. Bala K. Tripathy BC, Sharma D. Neuroprotective and Anti-ageing Effects of Curcumin in Aged Rat Brain Regions. Biogerontology 2006:7:81-9.

86. Yazawa K, Kihara $\mathrm{T}$, Shen $\mathrm{H}$, Shimmyo $\mathrm{Y}$, Niidome $\mathrm{T}$, Sugimoto H. Distinct mechanisms underlie distinct polyphenolinduced neuroprotection. FEBS Lett 2006;580:6623-8.

87. Rajeswari A. Curcumin protects mouse brain from oxidative stress caused by 1-methyl-4-phenyl-1,2,3,6-tetrahydropyridine. Eur Rev Med Pharmacol Sci 2006;10:157-61.

88. Dunsmore KE, Chen PG, Wong HR. Curcumin, a medicinal herbal compound capable of inducing the heat shock response. Crit Care Med 2001;29:2199-204.

89. Calabrese V, Guagliano E, Sapienza M, Panebianco M, Calafato S, Puleo E, et al. Redox regulation of cellular stress response in aging and neurodegenerative disorders: Role of vitagenes. Neurochem Res 2007;32:757-73.

90. Lim GP, Chu T, Yang F, Beech W, Frautschy SA, Cole GM. The curry spice curcumin reduces oxidative damage and amyloid pathology in an Alzheimer transgenic mouse. $J$ Neurosci 2001;21:8370-7.

91. Frautschy SA, Hu W, Kim P, Miller SA, Chu T, Harris-White ME, et al. Phenolic anti-inflammatory antioxidant reversal of Abetainduced cognitive deficits and neuropathology. Neurobiol Aging 2001;22:993-1005.

92. Ringman JM, Frautschy SA, Cole GM, Masterman DL, Cummings JL. A potential role of the curry spice curcumin in Alzheimer's disease. Curr Alzheimer Res 2005;2:131-6.

93. Adams BK, Ferstl EM, Davis MC, Herold M, Kurtkaya S, Camalier RF, et al. Synthesis and biological evaluation of novel curcumin analogs as anti-cancer and anti-angiogenesis agents. Bioorg Med Chem 2004;12:3871-83.

94. Lin L, Shi Q, Nyarko AK, Bastow KF, Wu CC, Su CY, et al. Antitumor agents. 250. Design and synthesis of new curcumin analogues as potential anti-prostate cancer agents. $\mathrm{J} \mathrm{Med} \mathrm{Chem}$ 2006:49:3963-72.

95. Sun A, Shoji M, Lu YJ, Liotta DC, Snyder JP. Synthesis of EF24-tripeptide chloromethyl ketone: a novel curcumin-related anticancer drug delivery system. $J$ Med Chem 2006;49:3153-8.
96. Capri M, Salvioli S, Sevini F, Valensin S, Celani L, Monti D, et al. The genetics of human longevity. Ann $N$ Y Acad Sci 2006; 1067:252-63.

97. Monti D, Salvioli S, Capri M, Malorni W, Straface E, Cossarizza A, et al. Decreased susceptibility to oxidative stressinduced apoptosis of peripheral blood mononuclear cells from healthy elderly and centenarians. Mech Ageing Dev 2000;121:239-50.

98. Salvioli S, Capri M, Scarcella E, Mangherini S, Faranca I, Volterra V, et al. Age-dependent changes in the susceptibility to apoptosis of peripheral blood CD4+ and CD8+ T lymphocytes with virgin or memory phenotype. Mech Ageing Dev 2003;124:409-18.

99. Hsu HC, Scott DK, Mountz JD. Impaired apoptosis and immune senescence - cause or effect? Immunol Rev 2005;205:130-46.

100. Fagnoni FF, Vescovini R, Passeri G, Bologna G, Pedrazzoni M, Lavagetto $G$, et al. Shortage of circulating naive CD8(+) T cells provides new insights on immunodeficiency in aging. Blood 2000;95:2860-68.

101. Brzezinska A, Magalska A, Szybinska A, Sikora E. Proliferation and apoptosis of human CD8(+)CD28(+) and CD8(+)CD28(-) lymphocytes during aging. Exp Gerontol 2004;39:539-44.

102. Capri M, Monti D, Salvioli S, Lescai F, Pierini M, Altilia S, et al. Complexity of anti-immunosenescence strategies in humans. Artif Organs 2006;30:730-42.

103. Zanni F, Vescovini R, Biasini C, Fagnoni F, Zanlari L, Telera A, et al. Marked increase with age of type 1 cytokines within memory and effector/cytotoxic CD8+ T cells in humans: A contribution to understand the relationship between inflammation and immunosenescence. Exp Gerontol 2003;38:981-7.

104. Vescovini R, Telera A, Fagnoni FF, Biasini C, Medici MC, Valcavi $P$, et al. Different contribution of EBV and CMV infections in very long-term carriers to age-related alterations of CD8+ T cells. Exp Gerontol 2004;39:1233-43.

105. Pawelec G, Koch S, Franceschi C, Wikby A. Human immunosenescence: Does it have an infectious component? Ann NYAcad Sci 2006;1067:56-65.

106. Calabrese EJ, McCarthy ME, Kenyon E. The occurrence of chemically induced hormesis. Health Phys 1987;52:531-41.

107. Calabrese EJ. Hormesis: from marginalization to mainstream: a case for hormesis as the default dose-response model in risk assessment. Toxicol Appl Pharmacol 2004:197:125-36.

108. Mattson MP, Cheng A. Neurohormetic phytochemicals: Low-dose toxins that induce adaptive neuronal stress responses. Trends Neurosci 2006;29:632-9.

109. Howitz KT, Bitterman KJ, Cohen HY, Lamming DW, Lavu S, Wood JG, et al. Small molecule activators of sirtuins extend Saccharomyces cerevisiae lifespan. Nature 2003;425:191-6.

110. Lamming DW, Wood JG, Sinclair DA. Small molecules that regulate lifespan: Evidence for xenohormesis. Mol Microbiol 2004:53:1003-9.

111. Sinclair DA. Toward a unified theory of caloric restriction and longevity regulation. Mech Ageing Dev 2005;126:987-1002.

Received October 11, 2006; accepted March 24, 2007 


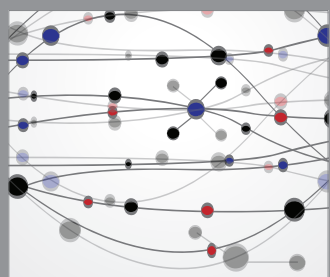

The Scientific World Journal
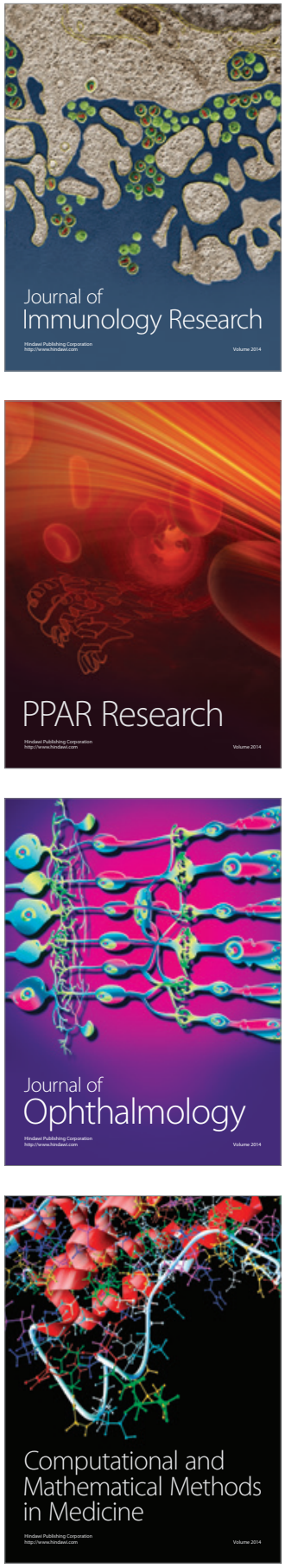

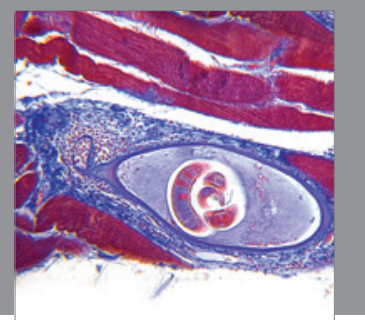

Gastroenterology

Research and Practice
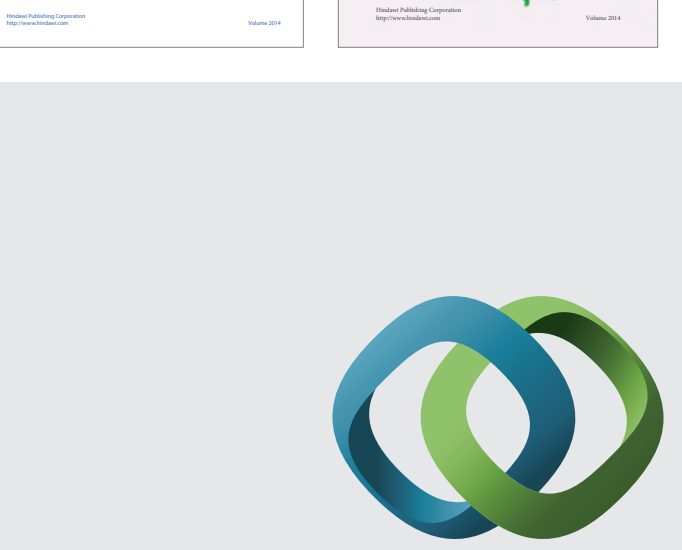

\section{Hindawi}

Submit your manuscripts at

http://www.hindawi.com
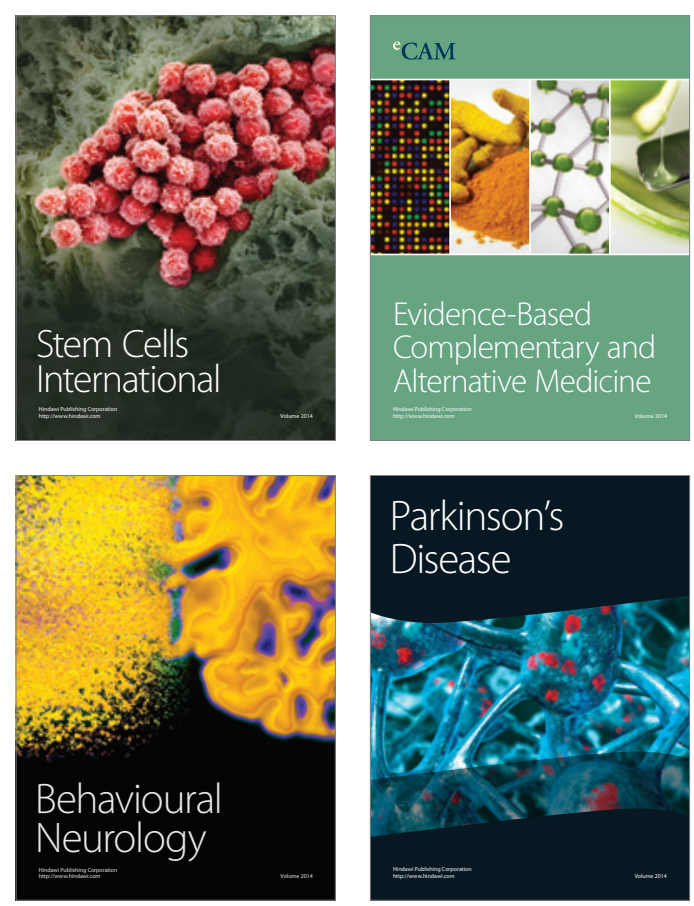

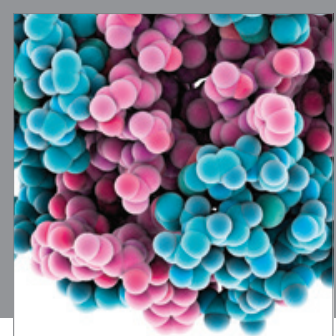

Journal of
Diabetes Research

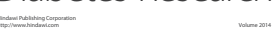

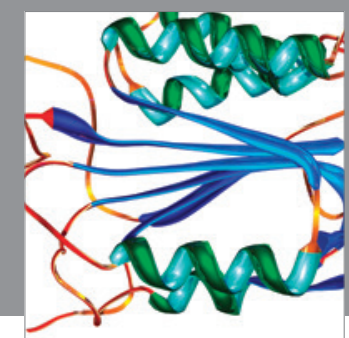

Disease Markers
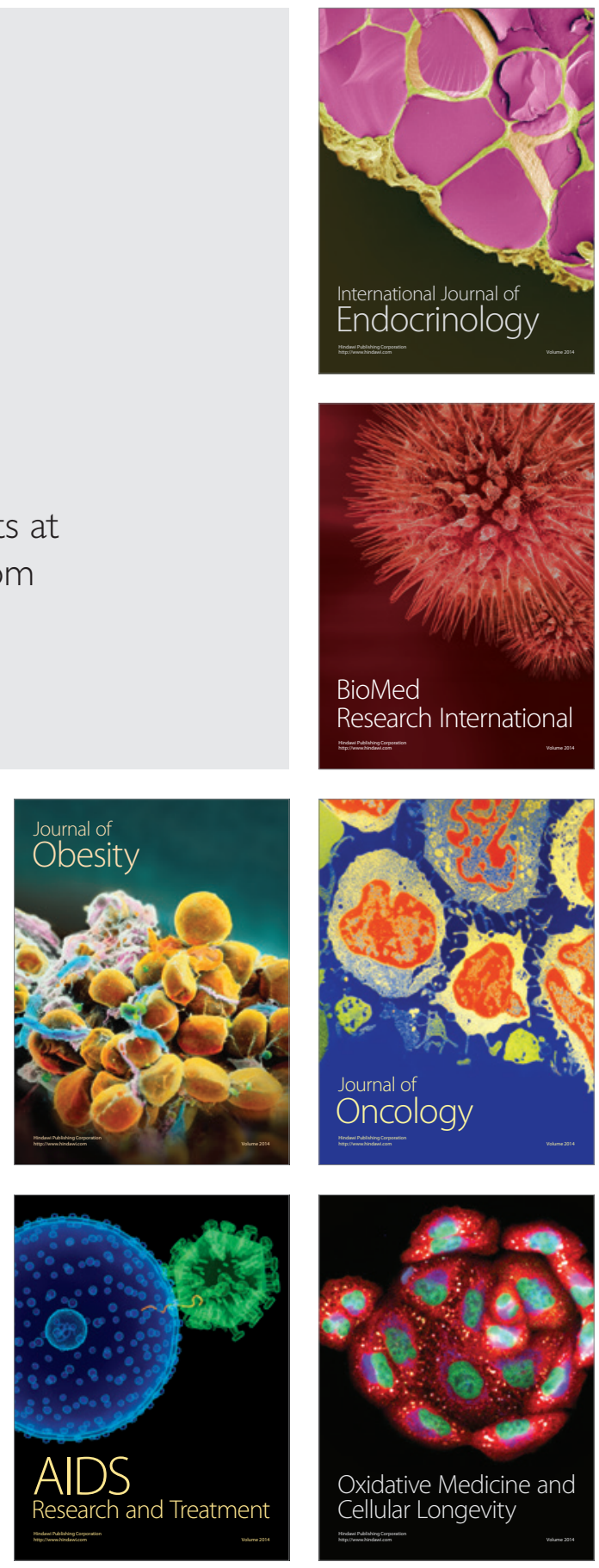